Secciōn central
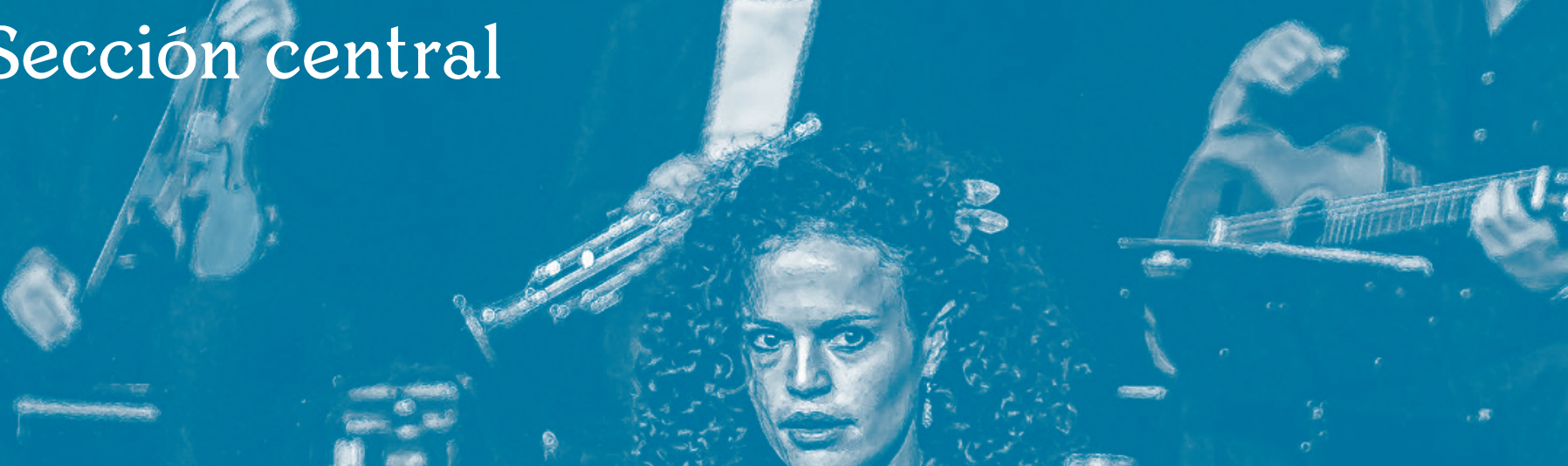

,
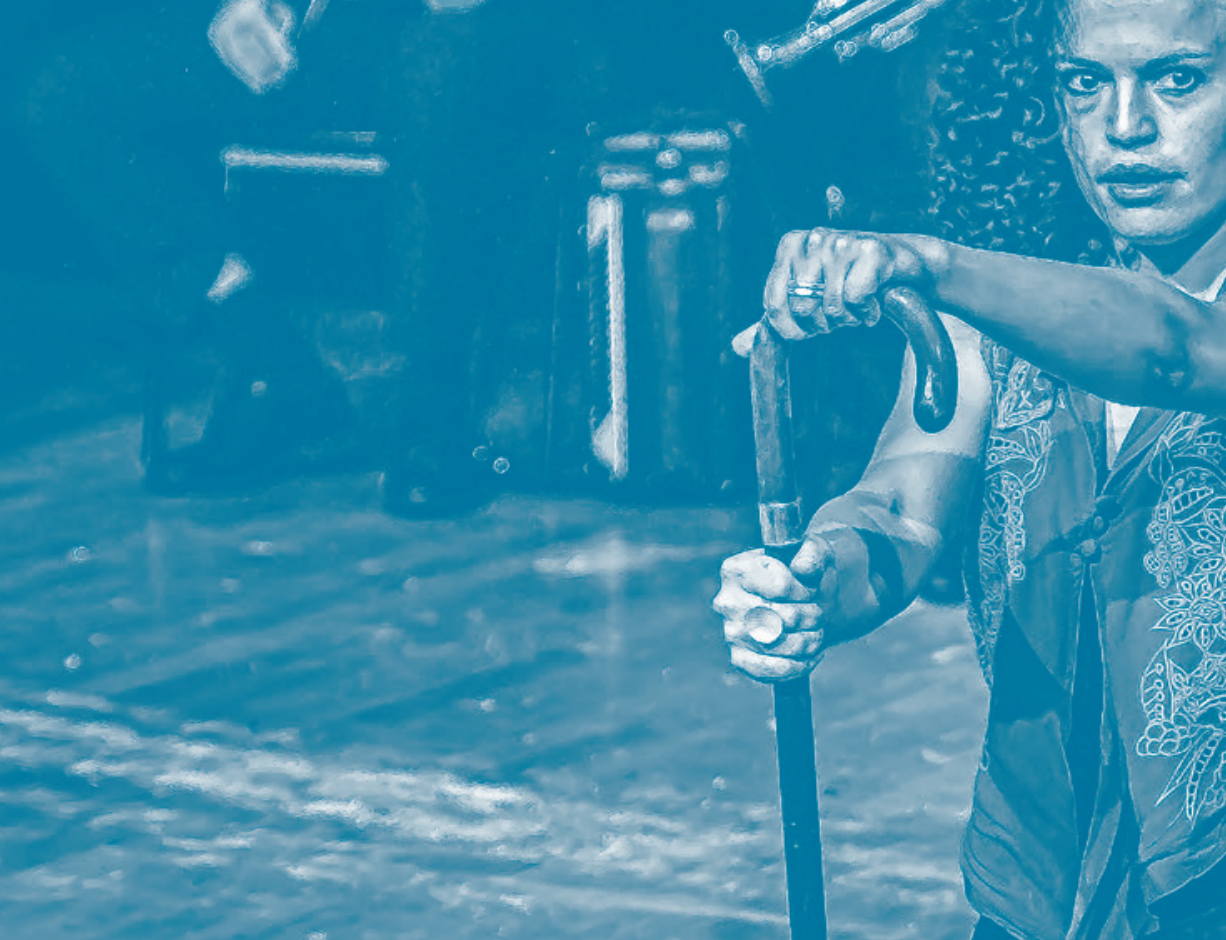

-
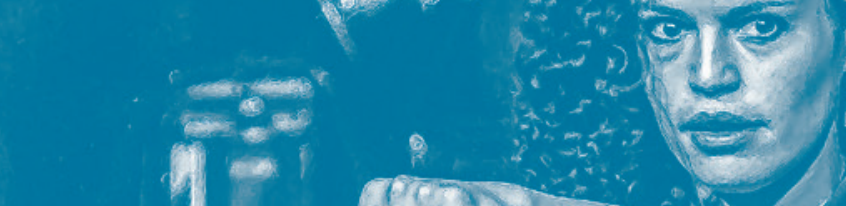

$f, y=1$
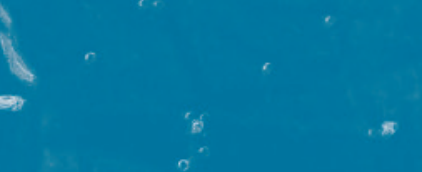

$x+3$
$x+3$

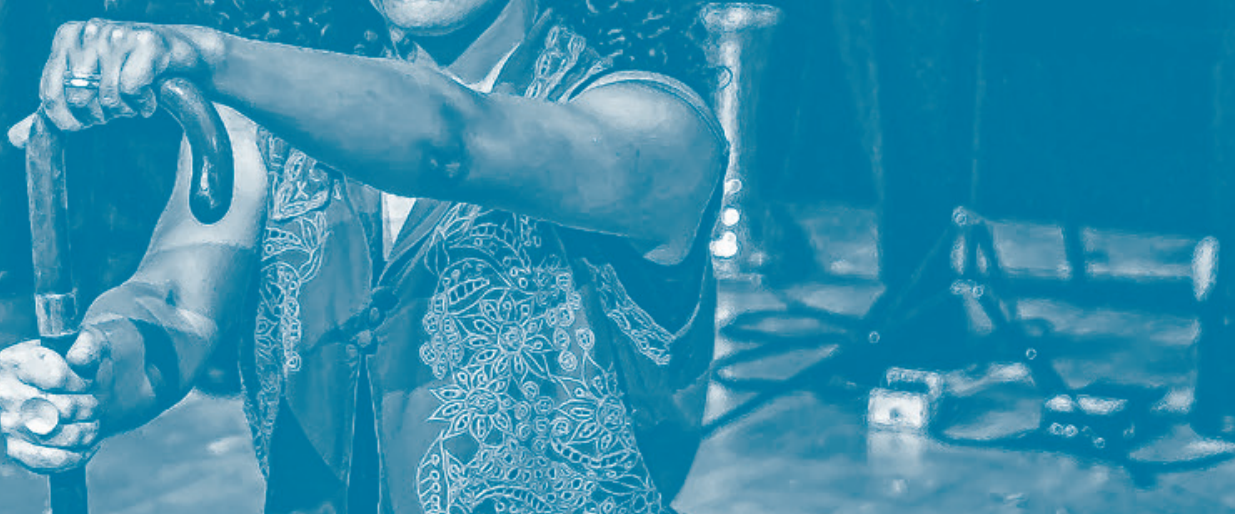




\section{El puente de los Vientos. Una pedagogía de la presencia}

\section{Artículo de investigación}

Recibido: 16 de julio de 2020

Aprobado: 12 de septiembre de 2020

\section{Sofía Monsalve}

Teatro de la Memoria, Colombia

filosofrita@gmail.com

Cómo citar este artículo: Monsalve, Sofía (2021). El puente de los Vientos. Una pedagogía de la presencia. Estudios Artísticos: revista de investigación creadora, 7(10) pp. 18-47.

DOI: https://doi.org/10.14483/25009311.17511

$<$

En la obra Las grandes ciudades bajo la luna, del Odin Teatret. (2013). Fotografía: cortesía de Tommy Bay.

\section{Resumen}

El artículo es una descripción y análisis del trabajo realizado por Iben Nagel Rasmussen, actriz del Odin Teatret desde 1966, y sus alumnos del Puente de los Vientos, durante más de 30 años alrededor del entrenamiento del actor y su trabajo con la energía y la presencia. En él se entrelaza la voz de la alumna con la voz de la maestra en un diálogo que busca, con palabras, dar la idea de la experiencia del Puente de los Vientos como grupo de investigación sobre el actor, en su búsqueda por la presencia.

\section{Palabras clave}

Odin Teatret; Iben Nagel Rasmussen; Puente de los Vientos; entrenamiento del actor; pedagogía de la presencia

\section{The Bridge of Winds. A Pedagogy of Presence}

\section{Abstract}

This article is a description and analysis of the work carried out by Iben Nagel Rasmussen, actress of the Odin Teatret since 1966, and her students from The Bridge of Winds for more than 30 years around the training of actors, and their relationship with energy and presence. We intertwine the voice of the student with the voice of the teacher in a dialogue that seeks, with words, to give an idea of the experience of The Bridge of Winds as a research group on the role of the actor and its search for presence.

\section{Keywords}

Odin Teatret; Iben Nagel Rasmussen; The Bridge of Winds; actor training; pedagogy of presence 


\section{The Bridge of Winds. Une pédagogie de la présence}

\section{Résumé}

Cet article est une description et une analyse du travail réalisé par lben Nagel Rasmussen, comédienne de l'Odin Teatret depuis 1966, et ses élèves de The Bridge of Winds depuis plus de 30 ans autour de la formation des comédiens, et leur rapport à l'énergie et présence. On entrelace la voix de l'élève avec la voix de l'enseignant dans un dialogue qui cherche, avec des mots, à donner une idée de l'expérience de The Bridge of Winds en tant que groupe de recherche sur le rôle de l'acteur et son besoin de présence.

\section{Mots clés}

Odin Teatret; Iben Nagel Rasmussen; The Bridge of Winds; formation d'acteurs; pédagogie de la présence

\section{A ponte dos Ventos. Uma pedagogia da presença}

\section{Resumo}

O artigo é uma descrição e análise do trabalho realizado por Iben Nagel Rasmussen, atriz do Odin Teatret desde 1966, e seus alunos da Ponte dos Ventos, durante mais de 30 anos de investigação sobre o treinamento do ator, seu trabalho com a energia e a presença. Nele se entrelaça a voz da aluna com a voz da professora em um diálogo que busca, com palavras, dar a ideia da experiência da Ponte dos Ventos como grupo de investigação sobre o ator, em sua busca pela presença.

\section{Palavras chave}

Odin Teatret; Iben Nagel Rasmussen; Ponte dos Ventos; treinamento do ator; pedagogia da presença

\section{Chakamanda wairakuna sug iachaikungapa ruraspa}

\section{Maillallachiska}

Kai pangapi kilkaspa parlakumi lben Nagel

Rasmussen, suti warmi pai ruraskata actriz del Odin Teatret kai watapi atun warranga iskun sugta sugta kaurra, pai tapuchispa ruraska kimsa chunga watapi nispa munaku parlangapa sug kunaua musukuna iachaikuspa ninakumi , imasami kai warmi kilkaska kai rurai waira chakamda suti.

\section{Rimangapa Ministidukuna}

Odin Teatret; Iben; Achka musukunaruraita katichigkuna; Nagel Rasmussen warmi chas suti; chakamanda wairakuna,ichaikuikuna; musukunata iachachidur

Primero el silencio, después el soplo: un pulso en el centro del pecho modela el aire. Los actores exhalan todos al mismo tiempo, al unísono, ritmo a tres cuartos.

El pálpito del pecho se manifiesta en los pies: pies listos para un vuelo. Los actores toman un mismo impulso, unidos por un pensamiento colectivo hecho cuerpo y de repente... el piso parece perder su dura consistencia y los actores saltan, como entre nubes. Como pájaros en bandada forman figuras en el espacio-cielo, guiados por esa inteligencia colectiva de sus cuerpos que respiran, por ese soplo palpitante que es aire saliendo de sus pulmones. El aire se transforma en canto, mientras los pies vuelan, las alas dibujan acciones en el aire. Acciones que brotan desde las profundidades del actor quien se abandona al viento y recuerda que, una vez, fue pájaro. La danza del viento ha comenzado.

En 1989 Iben Nagel Rasmussen, convocó a un grupo de personas para trabajar, durante un mes, en un proyecto teatral bajo el nombre International Seminar The Bridge of Winds. No podría imaginar que treinta años después se reuniría aún, de manera anual, con ese grupo de personas ( $y$ otras, que se fueron sumando a lo largo de los años) conformando una experiencia pedagógica y artística única en el mundo: El Puente de los Vientos. Tampoco podría imaginar que la danza del viento, creada en ese primer encuentro, y las cinco cualidades de energía se convertirían en una técnica de entrenamiento teatral que recorrería el mundo, como los vientos alisios y fundaría generaciones de actores que en ella encontraron un camino para la investigación, la formación y la creación. Lo que caracteriza el grupo es el desarrollo de una 
pedagogía única para la transmisión de las técnicas del actor y los caminos hacia la creación teatral, que resignifican la relación maestro-alumno. ${ }^{1}$ Iben Nagel Rasmussen nació en Dinamarca en 1945. Hija de los escritores Halfdan Rasmussen y Ester Nagel. El primero, una de las figuras más importantes de la poesía danesa del siglo XX. Iben, con un acercamiento al arte desde muy temprana edad, participó de los movimientos sociales de los años 60 en Dinamarca y junto con el movimiento hippie y la generación de poetas beat de ese país recorrió el mundo, acercándose a las drogas, al nomadismo, al arte callejero y... casi muriendo en el intento. A su regreso a Dinamarca ingresó al Odin Teatret, dirigido por Eugenio Barba que se acababa de mudar de Oslo (Noruega) a Holstebro, un pueblo recóndito en el noroeste danés. Iben recuerda:

Cuando, en 1966, llegué por primera vez al Odin Teatret como estudiante, me pusieron de inmediato y sin ninguna explicación previa a practicar ejercicios. Yo imaginaba que, al igual que en mi vida pasada, alguien en algún punto me explicaría el cómo y el porqué. Quedé desconcertada cuando simplemente tuve que imitar lo que los actores más viejos hacían. Ninguna filosofía, ningun significado profundo, simplemente hacer. Solo después de varias horas de trabajo intenso, recibíamos comentarios o correcciones por parte de nuestro director, Eugenio Barba, o de algún colega con más experiencia. ${ }^{2}$

1 En este escrito escojo la palabra alumno/a en vez de estudiante, discípulo o aprendiz, por su connotación directa con el maestro. Alumno es una palabra equivalente a discípulo, pero menos romántica en sus connotaciones. Y, sin embargo, la palabra que describe de manera más adecuada mi experiencia con Iben, sería pupilo/a. Es el pupilo el que vive en la casa del maestro -con connotaciones de huérfano en algunos casosIben me 'adoptó' como pupila en el 2007. Yo tenía 18 años y estaba entrando al Odin Teatret, empezando un camino como actriz dentro del grupo. Ella tomó completa responsabilidad de mi formación y de mi subsistencia. Vivimos juntas durante cinco años y la he acompañado en muchos de sus proyectos dentro y fuera del Odin. El mismo año en que me 'adoptó', entré al Puente de los Vientos. Las reflexiones de este escrito parten de esa experiencia.

2 El presente artículo es una descripción y análisis del trabajo realizado por Iben Nagel Rasmussen y sus alumnos. Todas las cursivas de este escrito representan la voz de la maestra y son sacadas del artículo "Las raíces de nuestro entrenamiento" de lben Nagel Rasmussen. Traducción del inglés de Sofía Monsalve. Publicado originalmente en The Book of Winds, Odin Teatret Forlag. Holstebro (Dinamarca), 2018.
Desde sus inicios, el Odin Teatret ha sido un grupo de autodidactas, (Eugenio Barba lo fundó convocando un grupo de jóvenes rechazados de la Escuela Nacional de Teatro de Oslo) es decir que los actores se han formado dentro del grupo y no en una academia o universidad. Este experimento autodidacta ha llegado hasta un punto en que el Odin Teatret sea hoy referencia mundial del teatro contemporáneo, no solo por sus impresionantes espectáculos que sacuden las fibras más profundas del espectador, por sus investigaciones en la antropología teatral, por la conexión con el teatro de grupo en Latinoamérica y Europa, o por las innumerables publicaciones y documentales sobre su gesta, sino porque se ha convertido en un referente para la pedagogía teatral.

Dentro del Odin se han creado las bases para la formación de actores bajo una lógica del grupo, la ética profesional, el estudio de técnicas somáticas (cuerpo-mente), la comprensión de los procesos orgánicos del actor y su papel activo en la creación. Al inicio, era el mismo Barba quien conducía los entrenamientos del grupo. Cuando fueron pasando los años, cada actor desarrolló su propio entrenamiento, su propia manera de entrar en sala y explorar, sistematizar y desarrollar las potencialidades de su cuerpo, su voz y las puertas que llevan a la creación. Así lo recuerda lben:

Cuando veía a Torgeir Wethal realizando el ejercicio denominado «El Gato» (una secuencia de ejercicios de yoga elaborada por Jerzy Grotowski y Ryszard Cieślak), no veía el ejercicio en sí, había algo más sucediendo en el cuerpo de Torgeir que me impactaba. (...) Su cuerpo se volvía transparente. Durante mis primeros años de entrenamiento en el Odin Teatret, yo no lograba encontrar aquel flujo y trasparencia (...) Me desesperaba pensando que nunca lograría encontrarlo.

Iben Nagel Rasmussen fue la primera actriz del Odin en emprender una vía personal de entrenamiento, y desde entonces ha sido la actriz-pedagoga por excelencia: quien ha asumido la mayoría de los procesos de formación de los actores que se han integrado al grupo.

Contemporáneo al trabajo con el Odin, Iben ha tenido varias experiencias teatrales externas, como lo fue el grupo Farfa y El Puente de los Vientos que hoy, treinta años después de sus inicios, se ha convertido en un proyecto de investigación, creación 


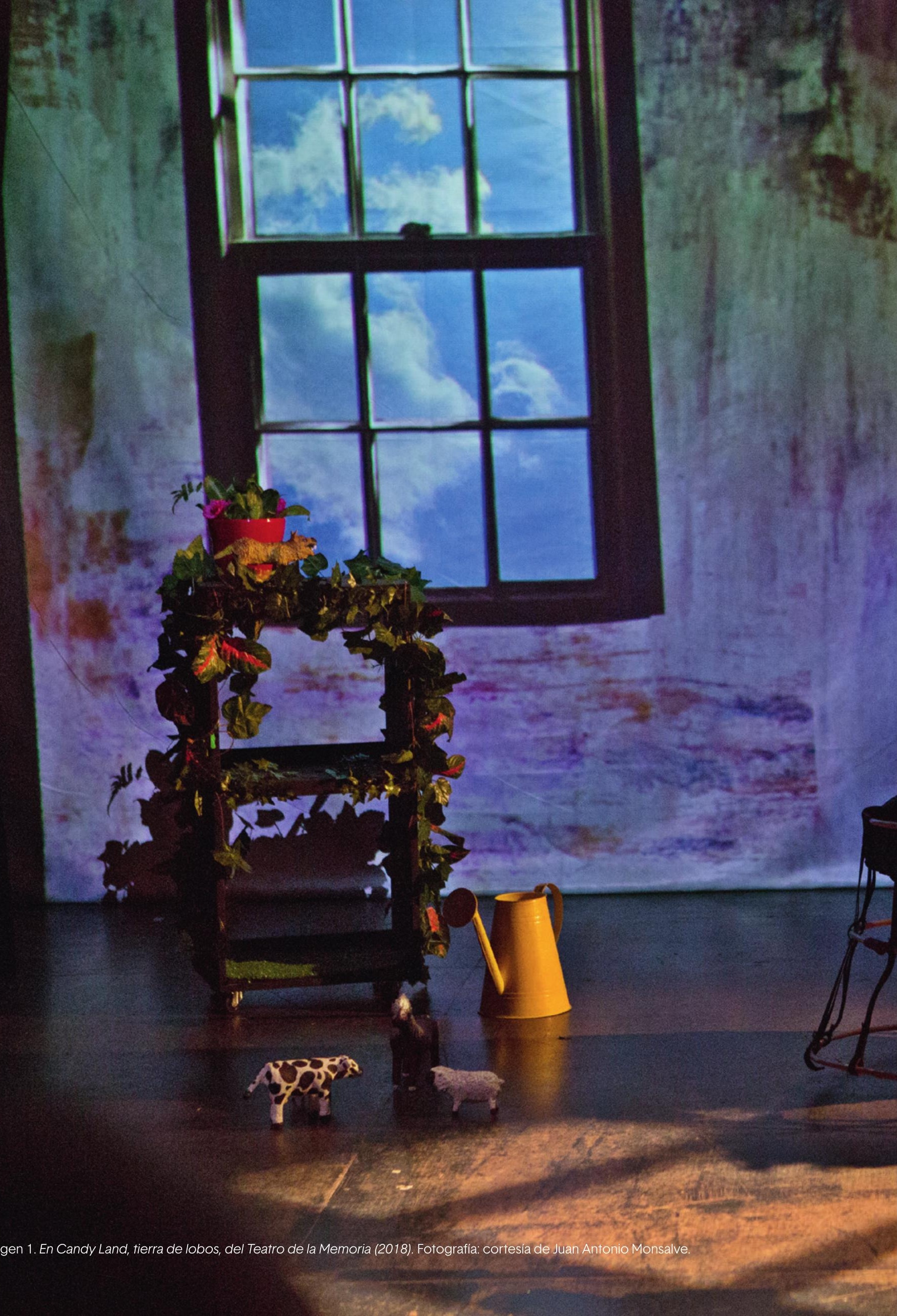


y formación de referencia que recoge la esencia de su trabajo, lo desarrolla y lo convierte en lo que podríamos Ilamar una tradición del quehacer teatral.

En la actualidad, El Puente de los Vientos reúne a 20 actores y actrices de Europa, Sudamérica y Asia en encuentros anuales que tienen lugar en diferentes partes del mundo. Durante los encuentros el grupo desarrolla técnicas de entrenamiento e investigación sobre el cuerpo y la voz del actor, se crean montajes teatrales e imparten seminarios.

\section{Cinco cualidades de la energía y el flujo que las conecta}

Por primera vez me pregunté a mí misma: ¿qué es una acción dramática? No en términos generales, sino qué es para mí. (...) Fue entonces cuando, finalmente, sola, aunque rodeada por mis colegas, encontré el flujo que por tantos años había estado buscando en mi entrenamiento.

Durante los encuentros anuales de El Puente de los Vientos, los miembros del grupo empiezan el trabajo diario con un espacio (entre una y dos horas) dedicado al entrenamiento físico. Este entrenamiento es el lenguaje del grupo. Los actores pueden regresar a la sala de trabajo después de un año sin verse, y aún así realizar una estructura completa, con una comunicación y escucha perfecta, como si solo ayer se hubiesen visto por última vez. La secuencia de los ejercicios y la energía colectiva creada por el grupo son más importantes que la expresión individual. La energía puede variar dependiendo de quién esté entrenando, qué animo tienen ese día, cuán cansados o activos están. Pero el objetivo principal es el de crear una energía al unísono en plena escucha y reacción. Estar juntos, sincronizar impulsos y acciones se vuelve más importante que demostrar habilidades y fortalezas personales.

La tesis central de esta exploración es: diferentes tipos de ejercicios desarrollan diferentes calidades de presencia escénica. Es decir, que, si un artista escénico entrena técnicas como el ballet, por poner un ejemplo, cualquier aparición en la escena estará inevitablemente coloreada con un determinado tipo de energía ligera y aireada. Por el contrario, si entrena técnicas cercanas a las artes marciales, su energía escénica tendrá otro talante, fuerte y bien enraizada. A partir de esta sencilla consideración, Iben inició la búsqueda de ejercicios que pudiesen ampliar las potencialidades expresivas del actor.

Hoy, después de más de treinta años, existe una estructura básica compuesta de 5 ejercicios y principios, dentro de los cuales los actores exploran y desarrollan acciones bajo diferentes cualidades de la energía. Cada ejercicio está compuesto por una serie de reglas y estructuras que, no obstante, su sencillez, permiten adentrarse en una exploración de largo aliento, a través de los años, y que parece no agotarse una vez dominado el ejercicio, para abrir nuevos caminos de exploración cada vez que se realiza.

Llevar a cabo acciones físicas concretas e improvisar con elementos previamente determinados, ayuda a construir aquel flujo constante, donde tanto el cuerpo como la mente del actor están completamente involucrados, posibilitando una conexión orgánica y no mediada por el intelecto, con las memorias profundas del actor, sus asociaciones de imágenes y estados emocionales. Con este entrenamiento, el actor consigue acceder a un gran espectro de variaciones de su cuerpo escénico, herramientas que puede luego aplicar a los personajes que él/ella, crean en la escena.

Si lo miramos bajo la terminología de la antropología teatral, el entrenamiento de El Puente de los Vientos desarrolla los principios de: transformación del peso en energía, alteración del equilibrio (equilibrio precario), precisión de las acciones y relación con el espacio, el ritmo y los otros actores en la escena. Desarrolla la habilidad de construir estructuras de acciones (partituras) vivas y precisas y la potencialidad de improvisar con ellas y descubrir variaciones; formando un comportamiento escénico que predispone al actor a ser concreto, efectivo y, al mismo tiempo, conectado con sus paisajes interiores y sus energías sensibles.

Me sorprendía ver la diversidad de estas danzas y cómo parecían expresar la vida interna de cada actor; sus fantasías y su asombroso coraje. Los actores, tanto aquellos con menos experiencia como los que tenían años de trabajo, parecían estar cabalgando un tigre salvaje, aferrándose a su cuello mientras creaban signos primitivos, casi «desesperados». 


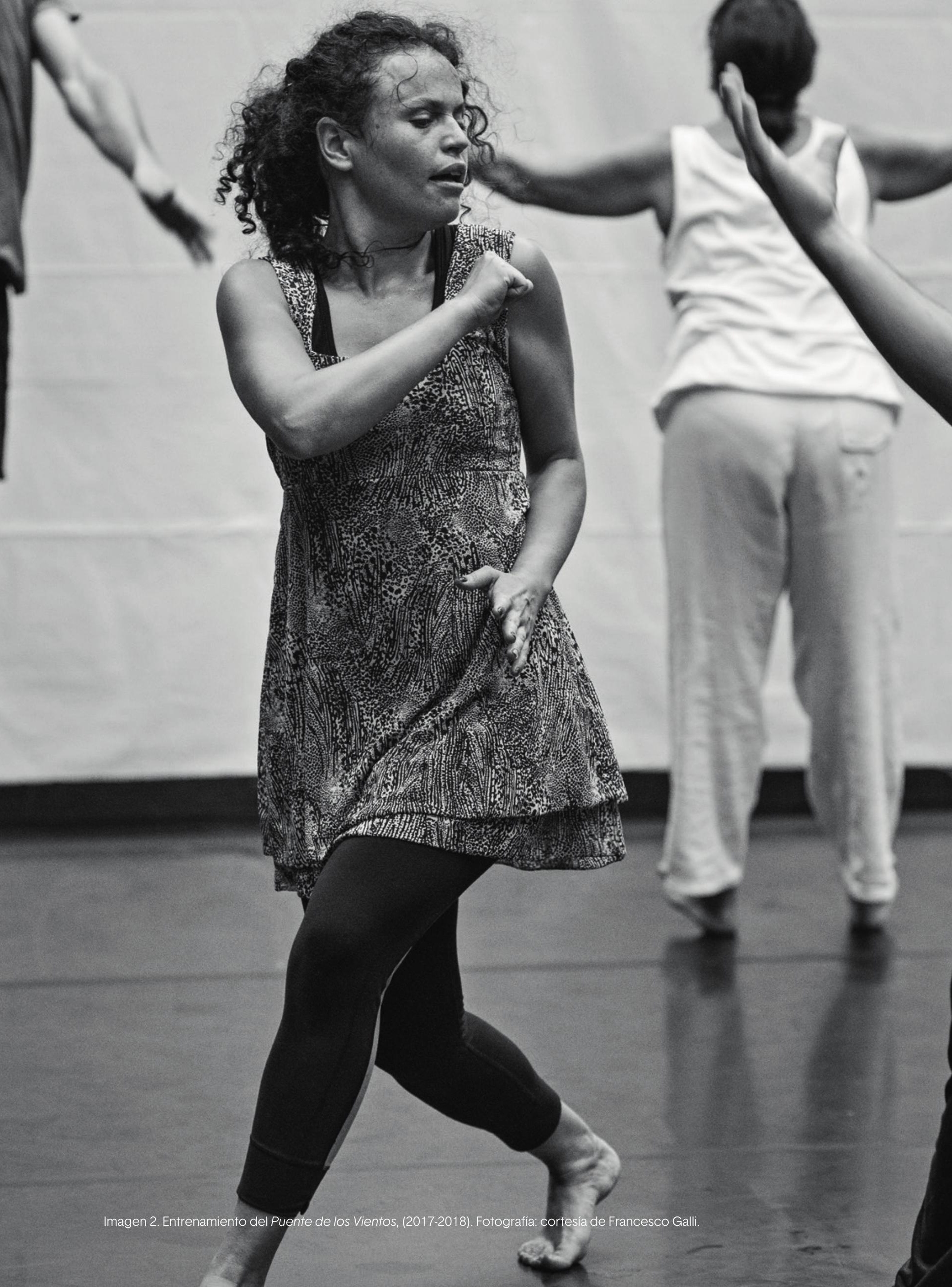




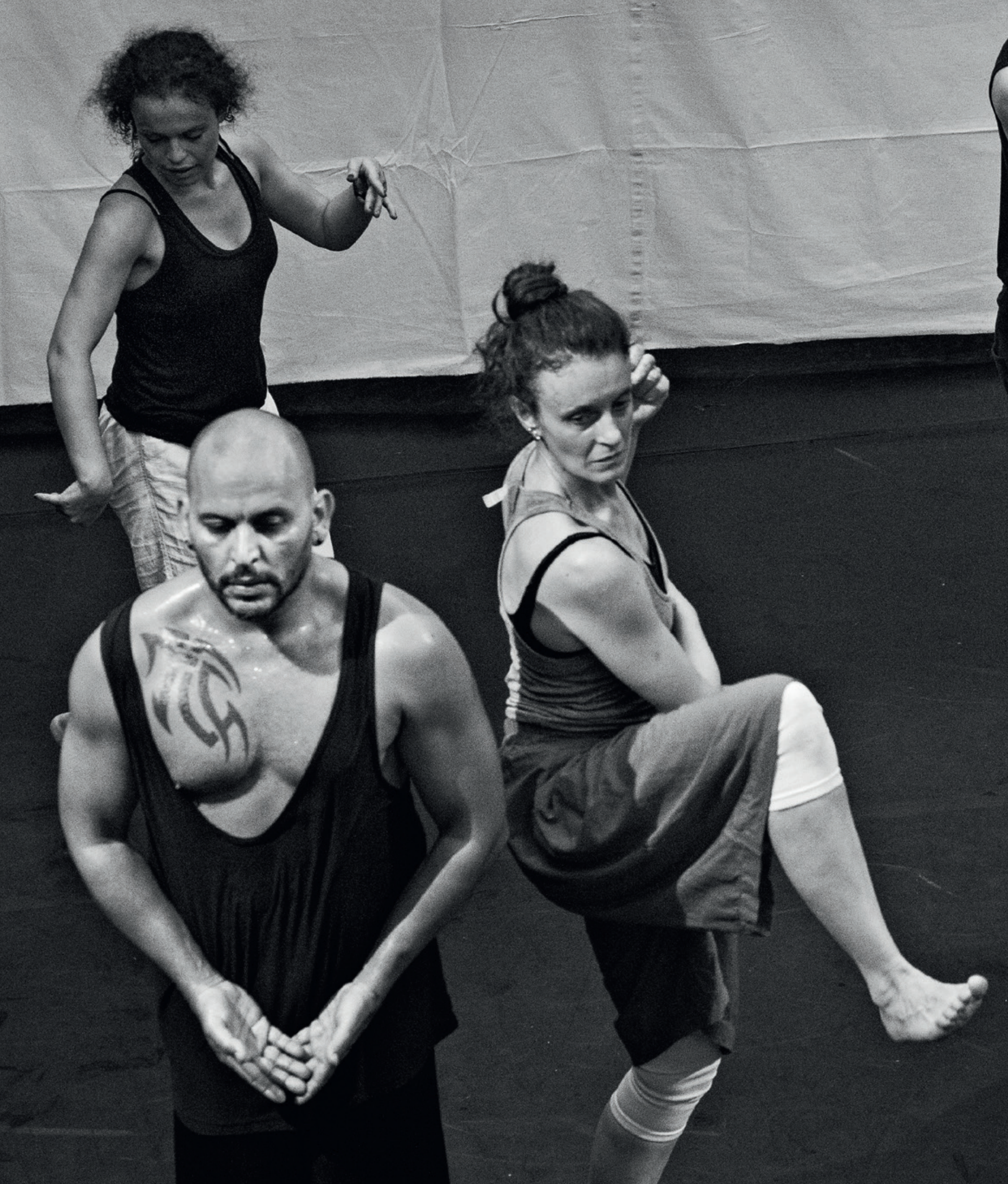

Imagen 3. Entrenamiento del Puente de los Vientos, (2017-2018). Fotografía: cortesía de Francesco Galli. 


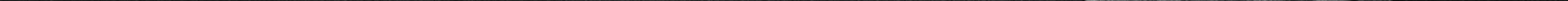




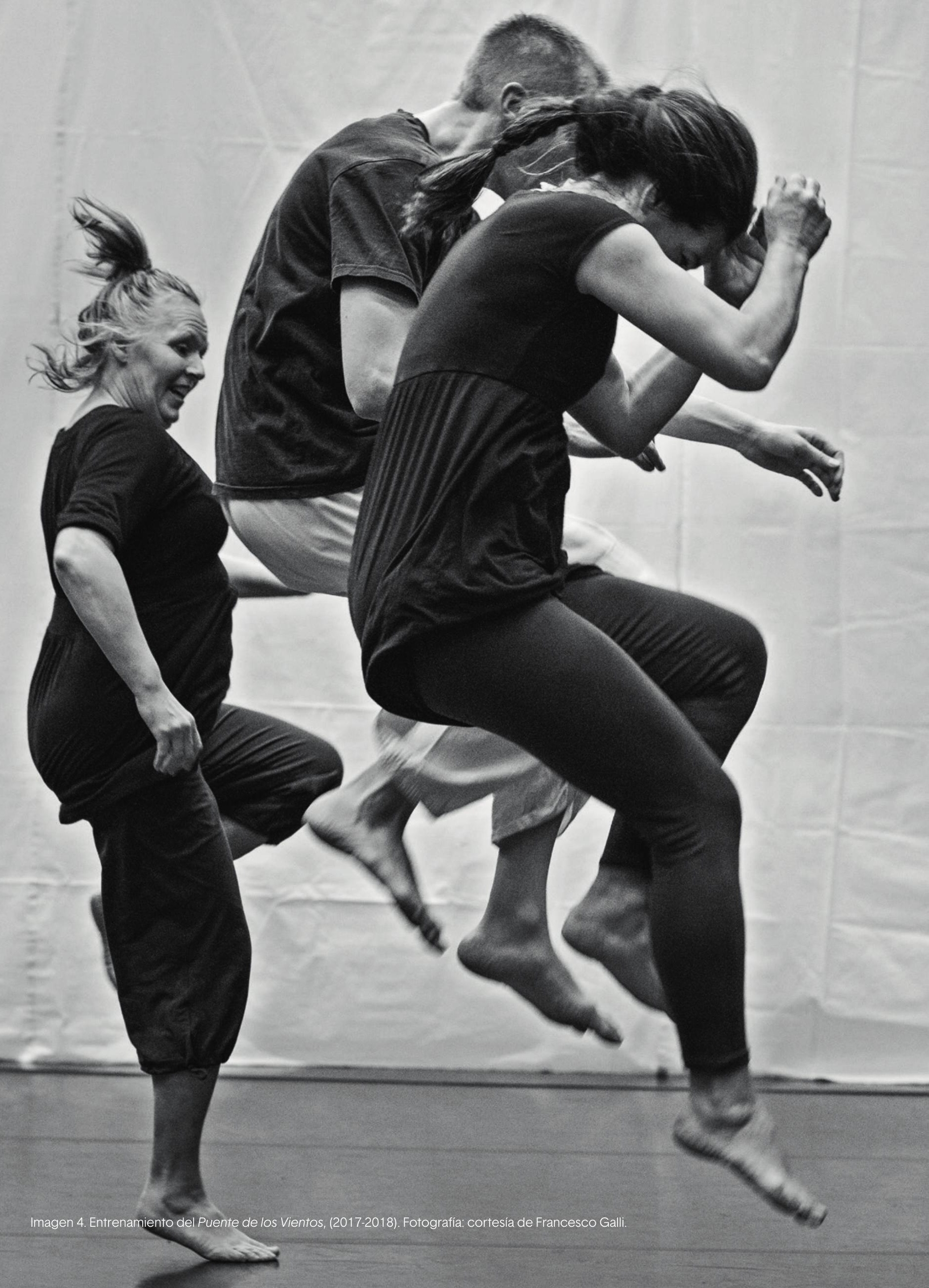




\section{Los ejercicios ${ }^{3}$}

Desgraciadamente, describir un ejercicio con palabras es completamente inútil, pero aún así...

Después de muchos años de investigación, hoy podriamos describir el entrenamiento como una serie de diferentes secuencias de ejercicios y principios de acción que los actores realizan, tanto individualmente como en conjunto. Se compone de: la danza del viento, la energía verde, los ejercicios del samurái, el slow motion y los ejercicios fuera de equilibrio. Cada ejercicio es un contenedor dentro del cual se desarrollan principios, habilidades técnicas, pero sobre todo relaciones escénicas: entre los participantes, con el ritmo, el espacio y el mundo interior del actor.

La musicalidad está presente durante todo el tiempo del entrenamiento, ya sea en forma de canto, respiración, silencios o melodías instrumentales con violín y flauta. Las transiciones de un ejercicio a otro siguen diferentes estrategias, ya sea transformando la energía de un ejercicio hasta llegar al siguiente, o realizando una acción conjunta que permite el cambio al siguiente ejercicio. En todos los casos se busca, fundamentalmente, no cortar ni segmentar el entrenamiento, sino construir un flujo constante entre estos. Es en la transición donde se desarrolla la capacidad de cambiar de energía escénica, permitiendo que el actor pueda componer acciones $y$, eventualmente, personajes complejos.

\section{La danza del viento}

Probamos la danza todos juntos: el paso y la exhalación. Después de algunos días comenzamos a modificar la dinámica (...) agregamos otros principios, como lanzar y atraer. Cada actor debía encontrar sus propias acciones. Trabajamos durante horas y horas, agregando los elementos a la danza. La nueva forma que tomó desparramaba energía, como flechas de luz en el espacio. El grupo entero se movía como un solo

3 Vale la pena anotar, que Iben, es una maestra muy cuidadosa con las palabras, aún más en la sala de trabajo, donde dichas palabras son amuletos. Por eso, como alumnos, hemos sido reticentes a escribir sobre el proceso pedagógico. El intento de describir una experiencia corpo-sensorial, maneras de organización del cuerpo-mente, acciones concretas, con palabras y conceptos, resulta mecánico y artificioso. Sin embargo, este artículo es el intento de crear puentes, si bien hechos de viento, entre la experiencia y la descripción de la experiencia. organismo viviente. La energía era generosa y, no obstante el cansancio, parecía extremadamente ligera. Por último, pero no menos importante: los actores podían danzar durante horas. Solos o juntos. Como un grupo de jazz improvisando, con notas específicas que se juntan, separan, tienen momentos de solo y de nuevo todos juntos en patrones impredecibles.

La danza del viento está compuesta de 3 pasos, más o menos simples. Parecido a un vals, pero transformando su estructura dinámica. En la danza del viento, al contrario que en el vals, un primer paso se realiza bajando el centro del cuerpo (yendo a tierra) con las rodillas bien dobladas, esto con el propósito de tomar un gran impulso (sats) y saltar con el segundo paso; el tercer paso tiene la función de transición para que el ciclo comience de nuevo. Creando así una estructura ternaria en constante renovación de energía. Para quienes conocen las danzas tradicionales colombianas, pueden imaginarse un paso simple de bambuco, solo que 'más profundo', donde el ejecutante realiza un gran esfuerzo bajando el centro de su cuerpo, para luego lanzarse al aire con un movimiento explosivo y que le permite un amplio y aireado desplazamiento en el espacio. Puede imaginarse una danza ritual de alguna comunidad amazónica (por ejemplo, los yukuna del Mirití Paraná), donde los ejecutantes entran en un ritmo cíclico marcado por una respiración común, un soplo que los mantiene unidos en un mismo pulso.

En la danza del viento los actores exhalan todos al mismo tiempo, marcando con la respiración el primero de los tres beats del ritmo. La exhalación no debe ser agotadora ni estridente. Es decir, que el actor no debe soltar su abdomen mientras suelta el aire, sino que debe tensionarlo ligeramente, dominando la calidad del soplo para que sea presente, pero no 'expresivo', para que no ralentice el ritmo, ni hiperventile al ejecutante. En pocas palabras, que no 'suelte la energía' mientras exhala. Este ejercicio desarrolla un tipo de energía ligera, donde el cuerpo del actor está constantemente 'despegando' del suelo en el acto de emprender el vuelo.

Puesto que es un ejercicio cíclico, debería ser realizado durante el tiempo suficiente para crear un arco energético en renovación, expandiendo los límites del cansancio y encontrando fuentes escondidas de energía. Es así como, en colectivo, se modela la energía de la danza, llevándola a picos fuertes 


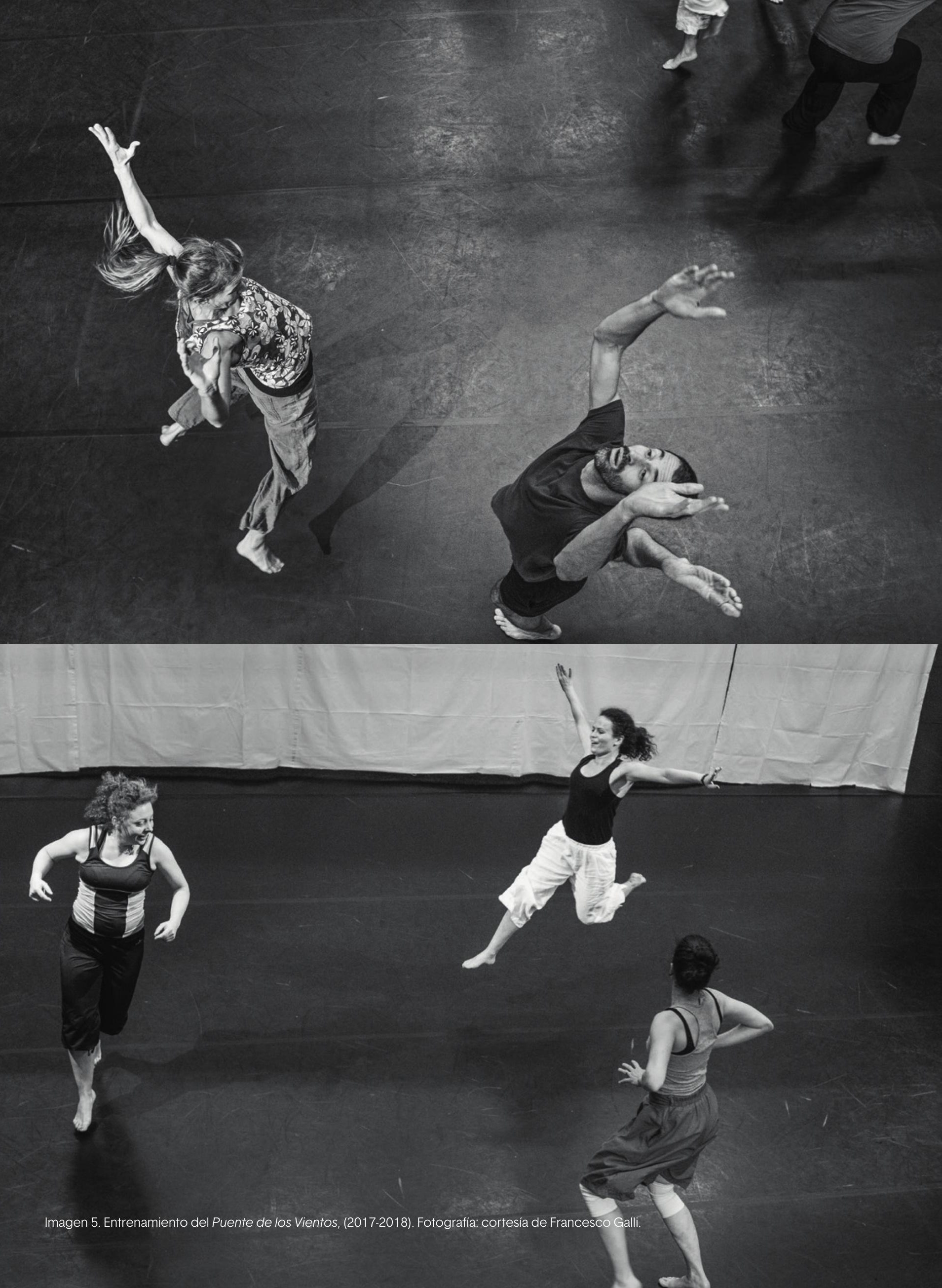


de mucho movimiento o reduciéndola a su mínima expresión; dejando que algunos actores desarrollen una improvisación en el centro o invadiendo todos juntos el espacio, como una gran marea que inunda una playa vacía. El objetivo no es el paso en sí, sino las puertas colectivas e individuales que abre.

La danza del viento se ha convertido en la base del entrenamiento. Crea un flujo colectivo en el cual los actores pueden desarrollar otros principios y acciones: stops (contención de la energía), maneras de lanzar, atrapar, e improvisar con objetos y materiales invisibles, crear relaciones dinámicas, espaciales y expresivas con los compañeros y permitir que en el cuerpo del actor se manifiesten imágenes, memorias, sensaciones, entre otras. Lo importante es mantener vivo un flujo sin interrupciones, de manera que las acciones se originen de ese mismo flujo y no desde una idea preconcebida, un cliché o un concepto intelectual.

Lo último, pero no menos importante: las acciones dentro de la danza siempre deben estar dirigidas a un punto específico del espacio o a los otros actores en la sala, volviéndola una danza de relaciones.

\section{La energía verde}

Este ejercicio está inspirado en la técnica básica de caminata del teatro Nō, en la cual el maestro retiene la cadera del actor con una correa, con el fin de generarle una resistencia. El estudiante deberá caminar sin mover las caderas, con el peso del cuerpo en el centro, manteniendo siempre la misma altura y el mismo carril, como si se deslizara sobre un riel.

El Puente de los Vientos ha tomado esta primera técnica de caminata del teatro japonés, para desarrollar un ejercicio que trabaja una calidad de energía lenta pero activa y una manera de moverse en el espacio como si el aire fuese denso, empleando una gran cantidad de energía para realizar la acción más simple. La condición de "empujar el aire" crea una presencia poderosa y contenida, cercana a los principios de la no-acción presentes en el teatro y la filosofía del Japón.

En la secuencia de entrenamiento, este ejercicio prosigue a la danza del viento. Es así como la transición entre estos dos ejercicios resulta un elemento fundamental del proceso, porque logra que toda esa energía ligera, burbujeante y explosiva de la danza del viento (con su respiración expandida y los músculos despiertos y calientes), deban 'contenerse' en esta nueva estructura, encerrándola al interior del cuerpo y trabajando la potencia y la fuerza desde su aspecto contrario: la retención.

De este modo, se logra una gran intensidad interior de la acción en su mínima expresión exterior. Durante este ejercicio, los actores caminan en el espacio (ya sea retenidos por un compañero o solos, simulando la retención) y realizan trayectorias simples tales como agacharse, retroceder, girar, levantar un brazo,... Casi no hacen nada y, sin embargo, su presencia es total, expandida dentro de la contención.

\section{El samurái}

Los ejercicios del samurái consisten en una serie de tres estructuras físicas básicas inspiradas en la imagen del guerrero japonés, con su pesada armadura, listo para la batalla. El actor mantiene las piernas abiertas en escuadra, el baricentro bajo y el torso recto; los brazos y los hombros relajados, aunque listos para reaccionar ante cualquier ataque. Sostiene un bastón de madera (real o imaginario) con ambas manos, lo que le ayuda a mantener la posición y la estructura corporal, y direcciona su foco de atención a puntos precisos del espacio escénico. Las tres estructuras básicas consisten en formas de desplazarse. La primera levantando una pierna a la vez y dejándola caer con gran estruendo (el lector puede imaginarse los pasos previos a la lucha del sumo), la segunda, en cambio, desliza los pies sin despegarlos del suelo, mientas gira todo el cuerpo en un bloque entero; la tercera levanta una pierna lateralmente y en una acción de ataque descarga todo el peso con un gran pisotón.

Después de haber aprendido estos tres pasos básicos, cada actor puede crear nuevas formas (saltos, giros, maneras de sentarse en el piso, entre otras), siguiendo los principios del samurái. Es importante que el actor fije detalladamente la forma inventada, que la codifique; para luego usarla como si fueran letras de un alfabeto físico: improvisando el orden, la dirección en el espacio, la calidad y tamaño del movimiento y su reacción a otras acciones de los compañeros. 

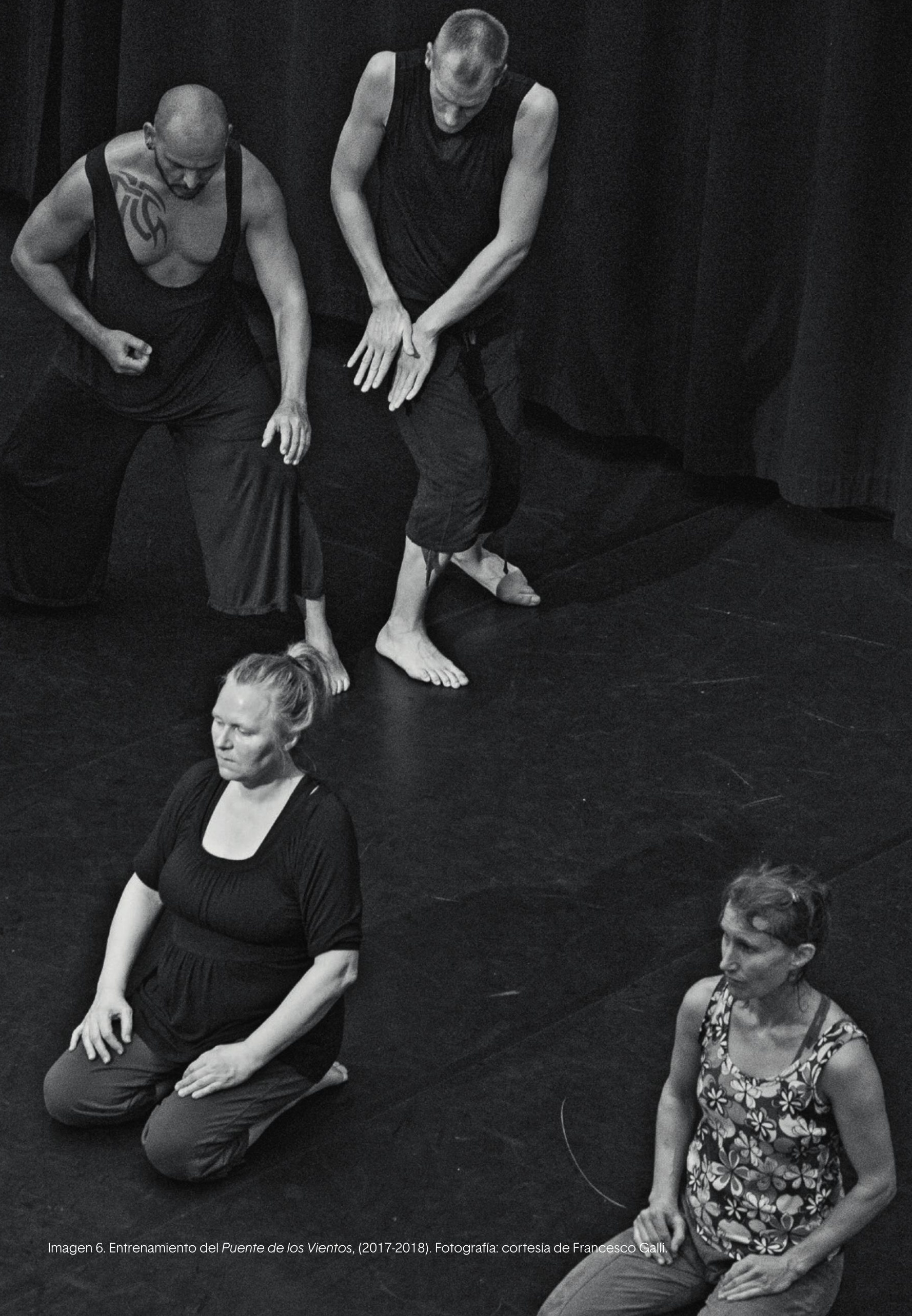
Uno podría comparar este proceso a la escritura de un poema, o a contar una historia sobre batallas, viajes, amores, a través de las palabras que existen previamente. Improvisar con elementos codificados ayuda a salir de los lugares comunes y profundizar en las relaciones y significados dentro de la acción, en vez de estar constantemente 'inventando' nuevas acciones sin permitirse ir al fondo de cada uno de sus detalles.

Los ejercicios del Samurái enseñan a componer el cuerpo en líneas rectas y ángulo claros, trasformar el peso en energía, siendo preciso, poderoso, concreto y desarrollar una energía enraizada, conectada con el suelo. Más allá de los aspectos técnicos, el imaginario del carácter fuerte, aunque noble, del guerrero japonés permite al actor explorar paisajes interiores de un lejano oriente imaginario.

\section{Slow motion}

El slow motion es una manera de moverse y actuar lentamente pero, al contrario de la energía verde, sin ninguna resistencia: como si el cuerpo estuviera bajo el agua o en el espacio exterior, sin gravedad, ni peso. Un movimiento lento pero ligero.

Todas las articulaciones están sueltas y las acciones son amplias, lentas y en un continuo flujo, sin impulsos ni contra-impulsos. Cada músculo del cuerpo sigue esta imaginaria gravedad cero, evitando tensiones inorgánicas. El objetivo de este ejercicio es encontrar la raíz interior de la acción. Todos los movimientos y acciones nacen en el centro del cuerpo y se expanden, como en una onda, hasta las extremidades. La respiración se torna profunda y expandida.

La dilatación del tiempo a sus más lentas expresiones obliga al actor a tener una completa consciencia de cada parte de su cuerpo, mientras que va encontrando formas orgánicas de direccionar el movimiento. Es así como este ejercicio permite un espacio silencioso, lento y dilatado de exploración, en donde la agencia del actor se suspende y es "algo más" lo que lo mueve. En este sentido, la tarea del actor está en escuchar su cuerpo y el movimiento que surge de él, dejando fluir las formas y que las asociaciones, imágenes y acciones lleguen sin provocarlas voluntariamente mediante el pensamiento.
Si bien este tiende a ser un ejercicio más solitario, la presencia de los otros actores en el espacio está constantemente influida por el movimiento personal. Es importante, entonces, no ensimismarse sino estar abierto y disponible a modificar una trayectoria, o reaccionar lentamente al impulso de otro actor en la sala. Como algas que a través del agua siguen juntas las ondas de mar.

\section{Out of balance (ejercicios fuera de equilibrio)}

\footnotetext{
Comencé a buscar diferentes maneras de sentarme, girar, dejar que mi cuerpo fuera al límite del equilibrio, cayendo al suelo y levantándome de nuevo. Los nuevos ejercicios se desarrollaban naturalmente, uno tras otro, en ondas continuas. Podía empezar rápido, luego cambiar a lento, ser fuerte y enseguida suave. La energía creada por el ejercicio me guiaba. Y yo me «olvidaba de mí misma» pero, al mismo tiempo, estaba siempre alerta.
}

En esta sección del entrenamiento cada actor deberá encontrar su propia serie de ejercicios fuera de equilibrio que luego improvisará en el espacio/tiempo. Los ejercicios se componen de tres fases: llevar el cuerpo al límite del equilibrio, al punto de casi caer al suelo; justo antes de perder completamente el control, el actor deberá recuperar el equilibrio llegando a una posición que bloquee la caída, reteniendo la energía potencial; finalmente, lanzando esa energía acumulada a un lugar preciso del espacio. En la transición a una nueva caída, el actor usa la energía acumulada de la caída anterior para entrar en un nuevo ejercicio.

El actor deberá fijar los ejercicios inventados e improvisar con ellos, encontrando innumerables variaciones en las transiciones de un ejercicio a otro. Es muy importante encontrar un nuevo inicio, después de cada final, de manera que se use la energía de la caída como el punto de partida de una nueva acción.

Una vez dominado un alfabeto básico de ejercicios fuera de equilibrio, el actor comienza a desplazarse en el espacio, lanzando bolas de energía y usando las transiciones con sus múltiples variaciones y dinámicas (lentas, rápidas, saltarinas, agresivas, contenidas, reducidas,) para componer acciones y trayectorias en el espacio. Aquí, de nuevo, la presencia de los demás actores se 

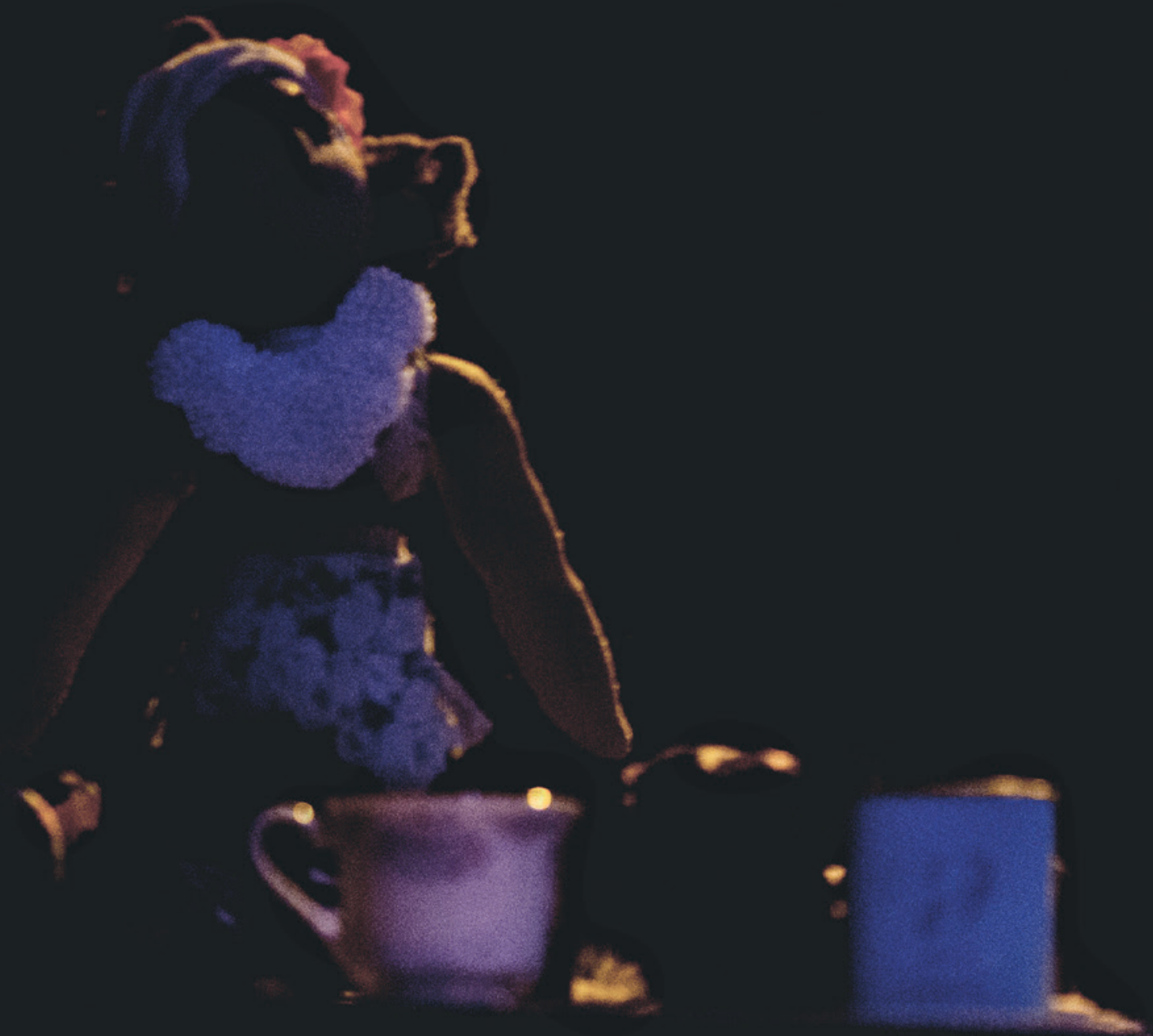

Imagen 8. En Candy Land, tierra de lobos, del Teatro de la Memoria (2018). Fotografía: cortesía de Juan Antonio Monsalve. 


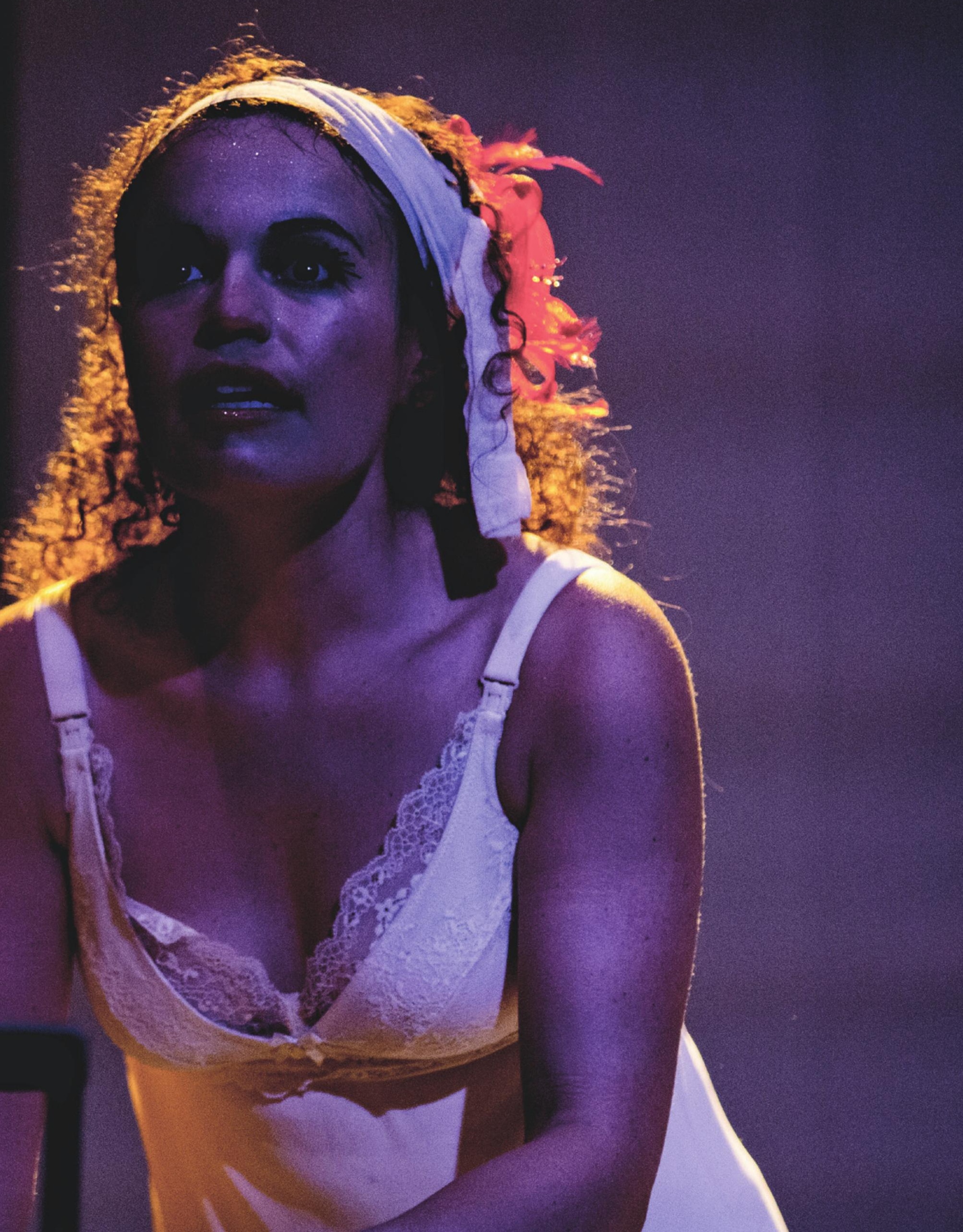




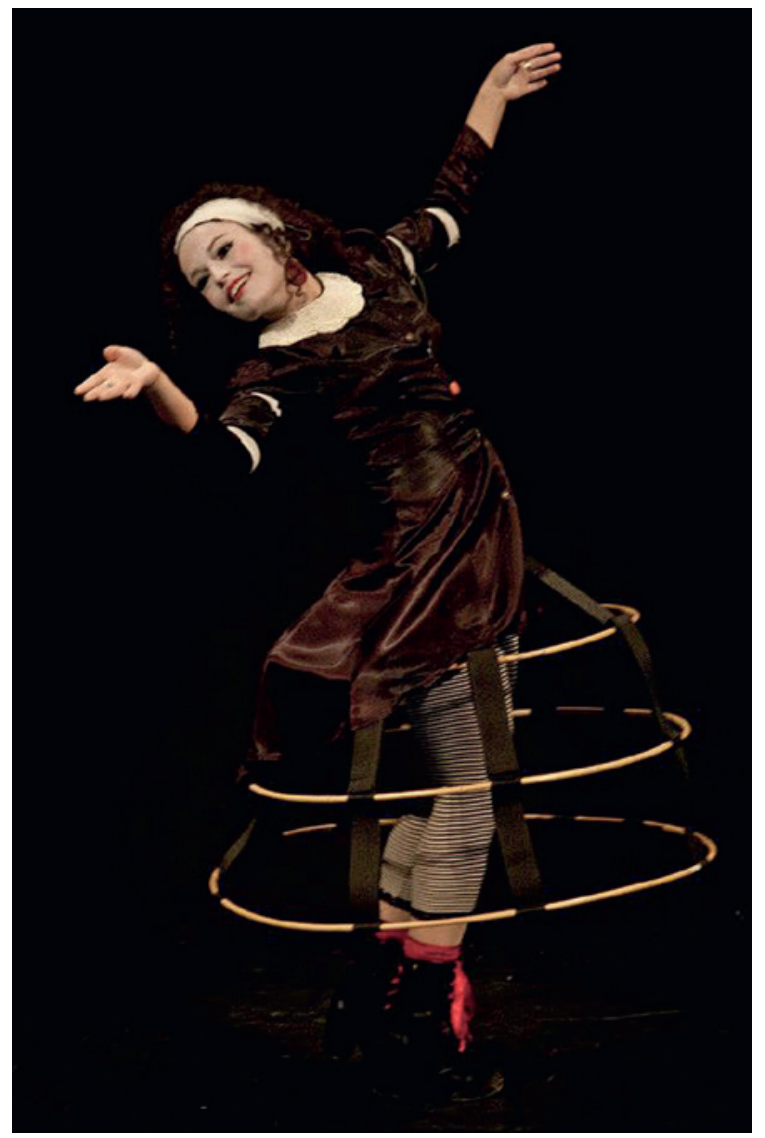

convierte en un estímulo para realizar el ejercicio, ya sea reaccionando en la distancia a la caída de un compañero o provocando una reacción con el proprio desbalance.

Al inicio de cada sesión, los actores acordamos el orden de los ejercicios a seguir, damos pautas concretas para que, una vez iniciado el entrenamiento, sea la escucha grupal lo que va definiendo orgánicamente el flujo de la sesión. Como en la escena, tratamos de seguir una curva dramática, con sus variaciones, pulsiones y aquietamientos. Lo importante es terminar cada sesión del entrenamiento, habiendo pasado a través de una 'experiencia', porque al final el espectáculo es eso: "la experiencia de una experiencia" (E. Barba, 2009).

\section{El aire y el silencio}

Podrán intuir, llegados a este punto, que todas las explicaciones que están leyendo sobre el
Imagen 9. En un trueque con el Odin Teatret, (2013).

Fotografía: Cortesia de Francesco Galli. ejercicio, el valor del mismo, los objetivos y los resultados esperados, nunca vienen dados a quien está practicándolo. Para quien tiene que ejecutar el ejercicio, estas informaciones son inútiles y eso Iben lo sabe muy bien. Es así como la indicación llega por medios sutiles.

Me tomó mucho tiempo descifrar cómo era la manera correcta de respirar dentro de la danza del viento. Después de unos pocos minutos de danzar, me dolía el bazo, tenía náuseas y, sinceramente, no se cómo lograba llegar al final del ejercicio. Iben solo nos decía que cuidáramos el 'soplo' para que no fuese tan fuerte porque la respiración del actor no debería ser 'expresiva'.

A un cierto punto y sin darme cuenta, mi problema de bazo se había resuelto y extrañamente ya no me mareaba durante la danza. ¿Milagro? No. La única manera de que mi cuerpo resolviera el acertijo de la gestión del aire era, precisamente, dejándolo que lo resolviera. 

Con el tiempo necesario y cuidando el aspecto 'audible' que me hacía notar mi maestra, mi cuerpo fue entendiendo que debía dejar entrar solo la cantidad necesaria de aire, relajando el abdomen y expandiendo el diafragma; y que al expulsarlo debía, por el contrario, tonificar los músculos del abdomen con el fin de exhalar controladamente y no perder la energía, obteniendo así ese soplo sutil que lben me demandaba.

Un tiempo después, una cantante de ópera me explicó cómo funcionaba la respiración diafragmática y isigue la misma lógica! (claro: sin estar saltando por el espacio como cabras salvajes). Luego, durante un periodo de estudios en Bali sobre técnicas de danza tradicional, descubrí que una de las razones por la cual la mayoría de las tradiciones teatrales en Oriente suelen aplicar fajas muy apretadas al abdomen del actor, es porque resulta una estrategia para reforzar la fuerza abdominal, hacerle oposición a la manera cotidiana de respirar y evitar que "se desperdicie el pranha, o la energía", en palabras de I Wayan Bawa, mi maestro balinés. Algo muy parecido a la activación abdominal que hacemos durante la danza del viento.

Pero claramente nunca hablamos de ello. Si Iben me hubiese explicado todo este aparato conceptual durante mis inicios en la danza del viento, estoy segura de que mi cuerpo habría hecho cosas extrañísimas, con el fin de poder controlar la respiración diafragmática. Habría generado tensiones innecesarias y, más importante aún, habría bloqueado el flujo de la danza.

Hoy, me doy cuenta de que solo cuando dejaba de pensar en la respiración, atrapada por la belleza de una acción, mi cuerpo encontraba las soluciones necesarias. Se necesita tiempo y una maestra que sepa dejar brotar la semilla, con la cantidad de agua necesaria. Ni más ni menos.

Iben observa el entrenamiento todos los días, en silencio. Ella toma algunas notas y solo después de finalizada la sesión dará algunas correcciones. Las palabras se eligen cuidadosamente. Indicaciones precisas, simples pero concretas, ayudan al actor a encontrar una manera de desarrollar su trabajo, mejorar detalles y calidades. No obstante, las indicaciones de lben son objetivas y basadas en observaciones específicas, tienen la capacidad de abrir las puertas hacia otro tipo de conocimiento: una conciencia profunda y que va más allá de las palabras. Cuando el actor se concentra en detalles precisos, la autoconciencia puede expandirse, dejando que sensaciones orgánicas, memorias y asociaciones aparezcan y tomen forma en el cuerpo del actor. El silencio es fundamental y las indicaciones de lben dirigen el camino del actor, sin cerrar las posibilidades con soluciones confeccionadas y respuestas prefabricadas.

Esta pedagogía del silencio subvierte los normales mecanismos de aprendizaje. Nuestra maestra sí enseña cosas, pero sobre todo escucha los caminos personales de cada actor. Es la seguridad que da su mirada, la ternura de sus "sí, por ahi" y la concreción de sus indicaciones y correcciones, lo que posibilita una búsqueda perseverante, tocando los propios límites y volviéndonos actores totalmente generosos en esa búsqueda.

Era importante que el impulso para encontrarlo viniera desde adentro de mí misma. Como dice el dicho: el maestro puede llevarte al umbral, pero no puede empujarte a través de la puerta. Tienes que hacer esa transición solo.

\section{La danza del viento en Colombia}

Desde que regresé a mi país, en el 2015, empecé inmediatamente a transmitir lo que había aprendido de mi maestra. Ya lo hacía en seminarios cortos alrededor del mundo, pero entendía bien aquello que tanto le preocupaba a lben en sus inicios como pedagoga:

Lo importante del trabajo era la duración, ser capaz de cultivar lo que siembras. Veía esas personas atoradas en donde estaban y sin medios para continuar. ¿Y si a mí me había costado cuatro años encontrar ese famoso «flujo», cómo podría llegar a transmitir este conocimiento? Claramente, no sería en un seminario de tres días.

Propuse entonces un espacio de entrenamiento tres veces por semana, al que llegaron inicialmente un grupillo de 8 jóvenes, algunos realmente muy jóvenes. Las técnicas propuestas eran las mismas de El Puente de los Vientos. El seminario pretendía durar solo un mes, pero se extendió, tres y luego casi seis meses de trabajo constante. Algunos chicos terminaban el mes de trabajo y no regresaban. Muchos otros se fueron sumando. Tuve que abrir otros espacios, nuevos grupos de 


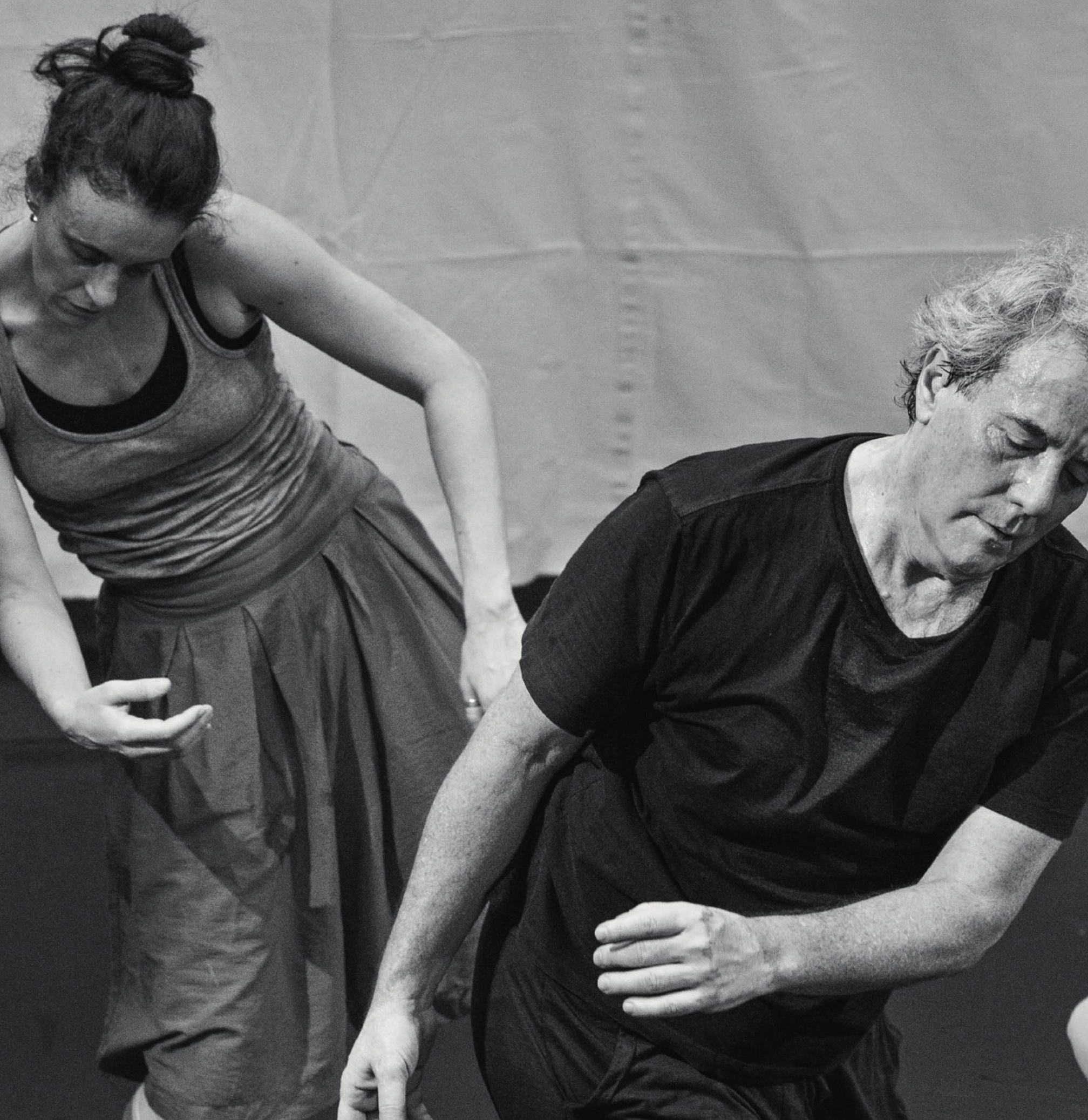




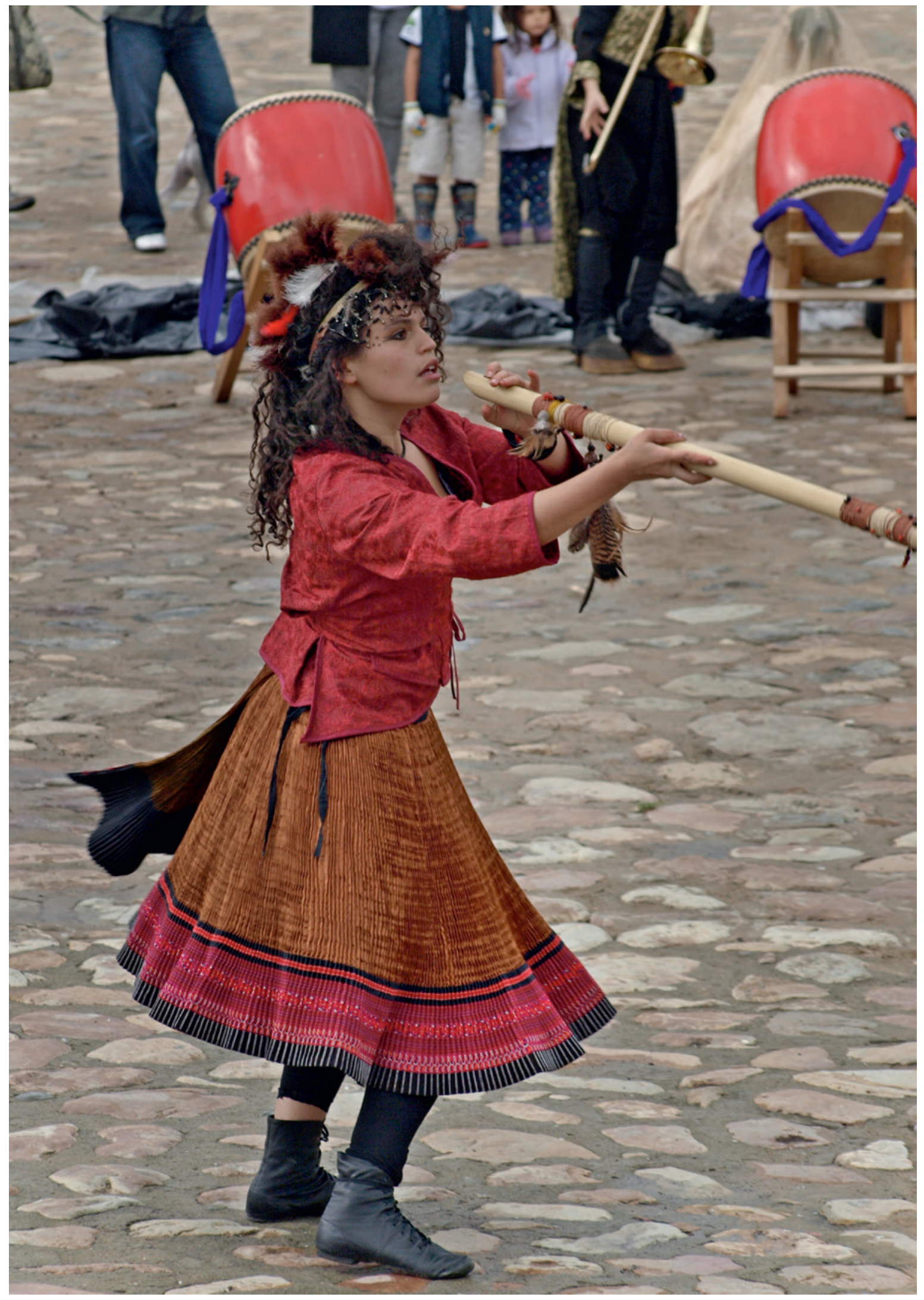

Imagen 13. En Ur-Nat, del Puente de los Vientos, (2010). Fotografía: Cortesía de Emilie Molsted Nørregard 
actores (o aspirantes) que buscaban este trabajo y se empeñaban en mantener una constancia, una puntualidad y nunca dejar de dar el cien por ciento de sus posibilidades. Entonces la constancia, esa cosa tan difícil de conseguir en estos tiempos y en estas latitudes, aparecía de una manera más orgánica. Como quien no quiere la cosa, han pasado ya varios años y nos seguimos encontrando. No puedo decir que estos jóvenes son un grupo, porque efectivamente los tiempos son fluidos, las necesidades variables, se va y viene. Pero, en el espacio del entrenamiento, han encontrado una clave de trabajo sobre sí: una experiencia rigurosa, creativa, donde sus posibilidades se expanden y sus energías se funden en un respiro común. Están juntos. Al menos por ese espacio de tiempo.

Y están juntos porque comparten una técnica, un lenguaje. He tenido la posibilidad de hacer encuentro con alumnos de muchos contextos diferentes y todos, sin conocerse, con edades y proveniencias distintas, toman aire al mismo tiempo y al mismo tiempo empiezan a danzar la energía. A entregarla generosamente y recibirla, a volverla acción y canto. Parece que se conocieran de toda una vida. Recuerdo sesiones de 50 personas en una sala de trabajo que, como miles de pájaros en bandada, atraviesan las nubes. La vida y su flujo se manifiesta.

Lo llamamos "el flujo". La energía creada por los ejercicios en el entrenamiento o las acciones en el espectáculo. Como agua en un río, debería siempre estar presente. Puede ser lenta o rápida. Puede represarse o convertirse en una cascada. Puede murmurar en el estrecho, o amplio, lecho del río. Pero si el agua se evapora, el río desaparece.

Algunos alumnos han ido quedando y han ido escogiendo este entrenamiento como su tradición, así como yo escogí a lben. Estoy segura de que una pedagogía del aire y del silencio, seguirá transformando actores aquí y allá.

\section{Referencias}

Nagel Rasmussen, I. (2018). Las raíces de nuestro entrenamiento en The Book of Winds. Sofía Monsalve (Trad.), Holstebro, Dinamarca: Odin Teatret Forlag.

Barba, E. (2009). Bruciare la Casa, Milano: Ed Ubulibri. 


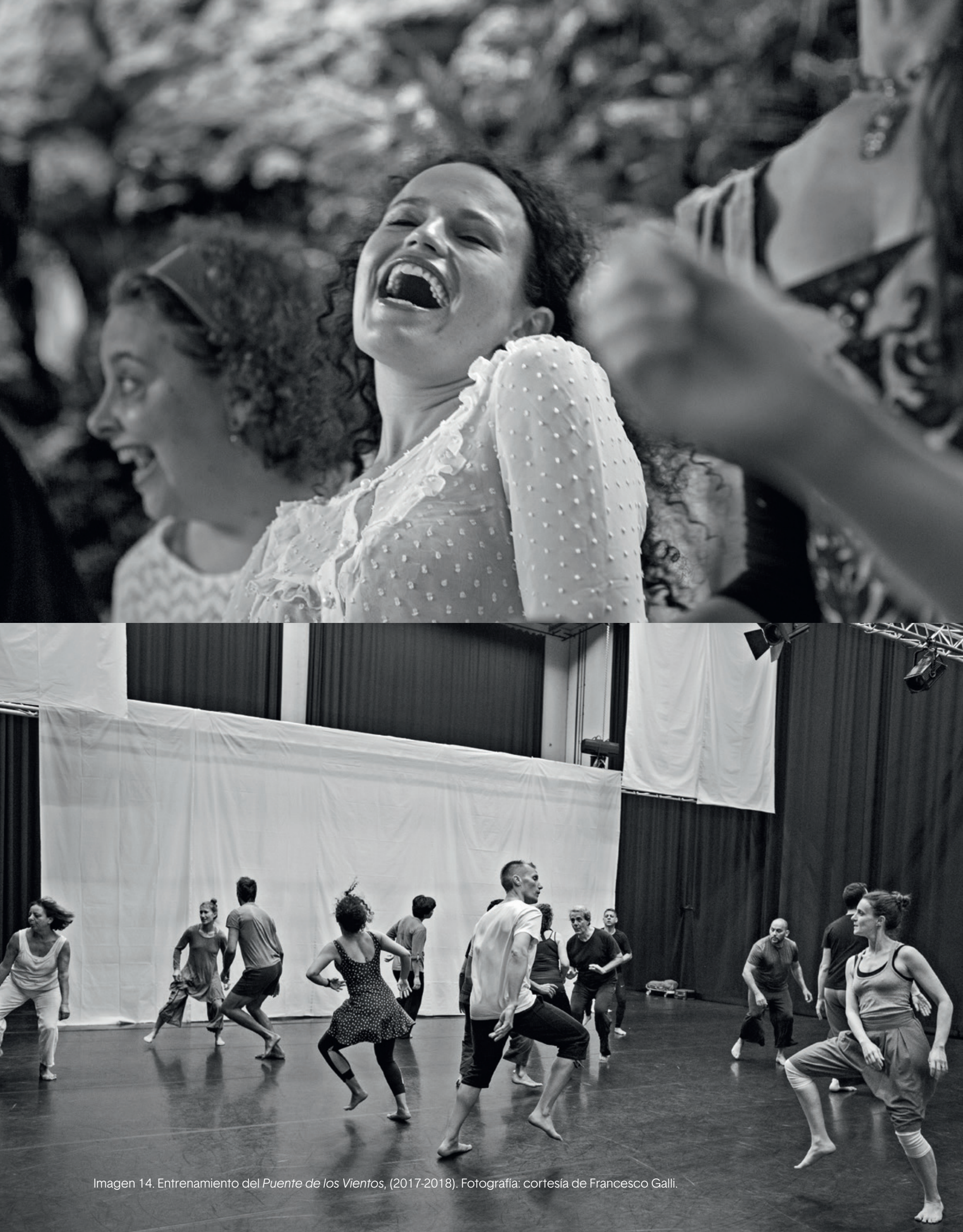




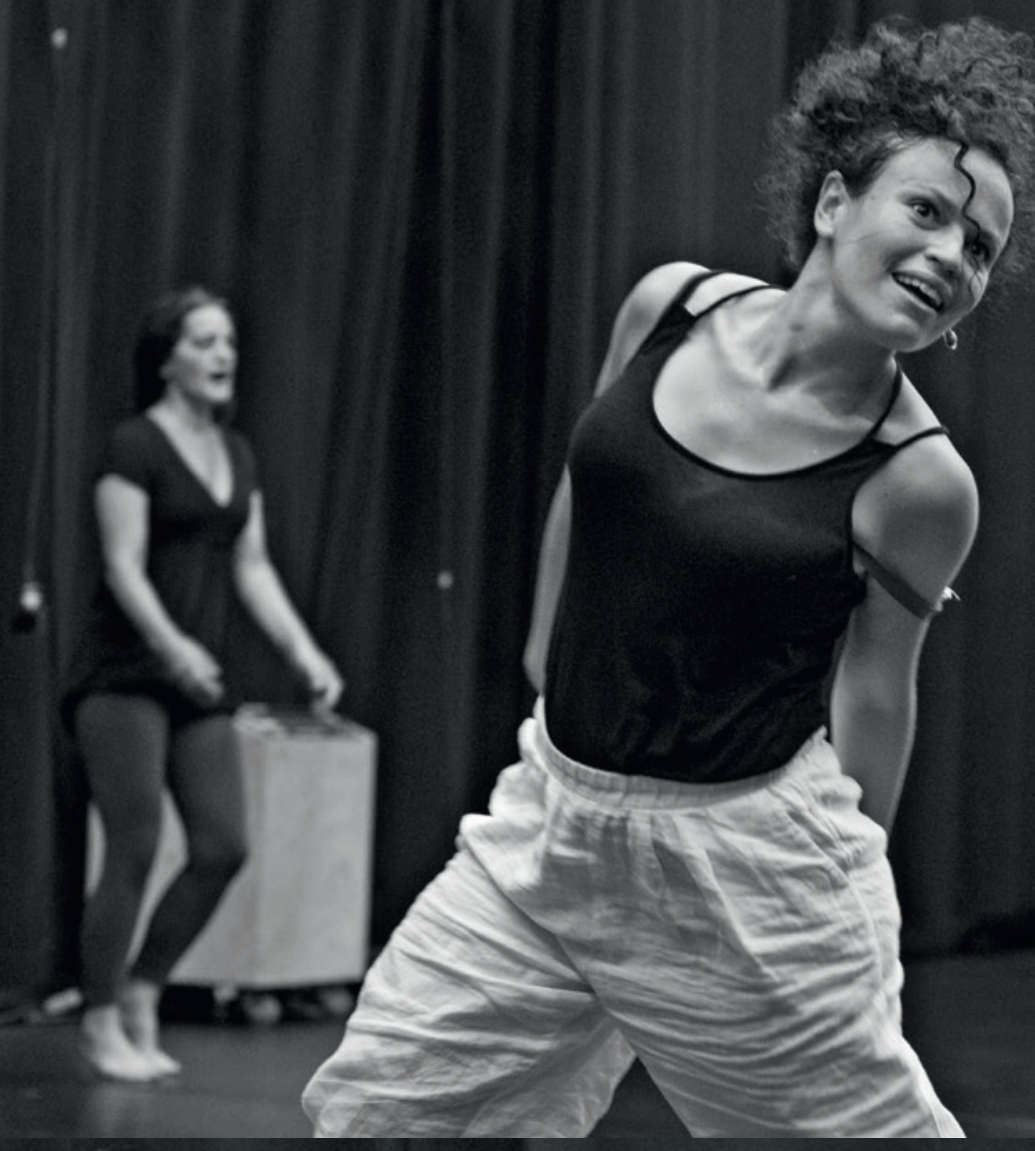

